\title{
The Fuel Cycle Implications of Nuclear Process Heat
}

\author{
Aiden Peakman ${ }^{1,2, *(1)}$ and Robert Gregg ${ }^{1}$ \\ 1 National Nuclear Laboratory, Chadwick House, Warrington WA3 6AE, UK; robert.wh.gregg@uknnl.com \\ 2 School of Engineering, University of Liverpool, Liverpool L69 3GH, UK \\ * Correspondence: a.peakman@liverpool.ac.uk
}

Received: 13 August 2020; Accepted: 11 November 2020; Published: 20 November 2020

check for updates

\begin{abstract}
International and UK fuel cycle scenario analyses performed to date have focused on nuclear plants producing electricity without considering in detail the other potential drivers for nuclear power, such as industrial process heat. Part of the reason behind the restricted applications of nuclear power is because the assumptions behind the future scenario are not fully captured, for example how big are demands from different sectors? Here we present a means to fully capture the potential opportunities for nuclear power using Sankey diagrams and then, using this information, consider for the first time in the UK the fuel cycle implications of decarbonising industrial heat demand in the year 2050 with nuclear power using the ORION fuel cycle code to study attributes related to spent fuel, uranium demand and decay heat from the spent fuel. We show that even in high industrial energy demand scenarios, the sensitivity of spent fuel masses and decay heat to the types of reactor deployed is relatively small compared to the greater fuel cycle demands from large-scale deployment of nuclear plants for electricity production. However, the sensitivity of spent fuel volumes depends heavily on the extent to which High Temperature Reactor and Light Water Reactor systems operating on a once-through cycle are deployed.
\end{abstract}

Keywords: fuel cycle; nuclear; process heat; ORION; spent nuclear fuel; HTR; SFR; SMR

\section{Introduction}

Much of the energy scenario modelling, and accompanying fuel cycle assessments, performed to date (not only in the UK) have focused solely on nuclear power plants being used for electricity supply [1-3]. The scenarios also consider varying amounts of demand for electricity from nuclear; for example, in the UK, fuel cycles between 16 GWe and 75 GWe have been investigated [1,4]. This analysis suffers from a key drawback: It is not always clear how a particular scenario has been derived, for example what is driving the increase demand in electricity and the deployment of nuclear power plants? The answer to this point is important, since it may be the case that nuclear power is not being considered for applications it could readily fulfil, for example is growth in industrial heat demand and the assumed electrification of industry driving electricity demand? If so would it be possible to employ nuclear power plants for direct heat applications rather than indirectly via electrification? Furthermore, which nuclear reactor types would be most suitable for industrial heat applications? This lack of clearly defined context surrounding the scenario weakens the overall analysis.

Given the above, the key aims in this investigation are to: (1) develop a scenario with significant industrial energy demand in the UK by 2050; and (2) extend this scenario into other scenarios by identifying what is causing the demand and therefore systematically consider for the first time the role of nuclear power in other scenarios, along with the associated fuel cycle implications. In the analysis presented here, scenarios are derived with the drivers clearly outlined. The scenarios firstly assume no direct application of nuclear heat but the energy demand from different sectors in the UK (including transport, heating and lighting \& appliances), with a high proportion of industrial heat 
demand, is determined for the year 2050. The initial scenario was developed around the Pathway Analysis summarised in Ref. [5], which targeted greenhouse gas (GHG) emission reductions of $80 \%$ relative to 1990 levels by the year 2050. Note that the scenarios considered here are not meant to be predictions but help understand the implications in the event there is a high demand for low-carbon energy to meet high levels of electrification and industrial heat demand, with nuclear power playing a central role.

Starting from this initial scenario, the suitability of different reactor technologies for heat applications are considered. Then, by determining the role of different reactor technologies within the initial scenario, this information is used to consider a bounding case with a high proportion of direct nuclear heat used within industry and the impact on GHG emissions also assessed.

When assessing the feasibility of any future scenario it is important to consider the fuel cycle implications, which includes: determining the resource demands associated with operating the reactors for many decades; and the characteristics of the waste. For these reasons, fuel cycle codes are employed [1]. In this investigation the fuel cycle implications for the scenario with direct nuclear heat used within industry are considered in detail, using the UK fuel cycle code ORION $[1,4,6]$, based on scenarios relating to degrees of uranium scarcity and potential policy drivers relating to the management of spent fuel. Given the recent motivations to target GHG emission reductions of around 95\% [7], pathways to further reductions in GHG emission are also outlined to build on the original analysis and highlight the potential role for hydrogen and Carbon Capture and Storage (CCS) to further limit GHG emissions.

\section{Method}

\subsection{Details of Energy Scenarios}

The energy scenarios considered in detail here relate to those with high proportions of electricity demand outlined by the UK government in Ref. [8] but with modest levels of electrification in industry. These so-called "electricity pathways" assume the following [5]: (1) Electricity is the main source of energy in 2050. (2) There are many more electric vehicles (EVs); gas boilers are predominantly replaced with electric heating; and industry moves to cleaner fuels. (3) In this pathway, CCS plays only a limited role by the year 2050 .

As previous work [1] has considered high electricity consumption but not the role of industrial heat, the work outlined here focuses on scenarios with high proportions of industrial heat demand since these are the scenarios where technologies (such as nuclear reactor systems) will have the greatest role to play in industrial applications. Furthermore, if scenarios with limited or negative industrial growth result in the UK simply importing more goods from other countries, it is still important to consider the role low-carbon technologies could play-ultimately for global greenhouse emission targets to be met, all countries will have to adopt low-carbon means to manufacture goods.

All electricity pathway scenarios also make the following key assumptions for the year 2050 [5]:

1. Electricity is a significant low-carbon energy source to the industry sector, making up around one-third of fuel demand. This is lower than other scenarios considered for the UK, where up to around two-thirds of industrial energy demand is met via electricity but allows for the role nuclear power can play in providing direct nuclear heat to be investigated.

2. $100 \%$ of kilometres driven in cars and vans is via battery electric vehicles, i.e. no hydrogen fuel cell electric vehicles and no hybrid cars or vans. Such high levels of electric vehicle deployment may be considered optimistic but have been considered in previous UK scenario analysis [5]. Furthermore, in the context of other studies, around $90 \%$ of light-duty vehicles have been considered to be decarbonised via Battery Electric Vehicles (BEVs) and fuel-cell vehicles by 2050 in [9], and $82 \%$ of light-vehicles (via 75\% BEVs and 7\% plug-in hybrid electric vehicles) in [10].

3. Electricity generation is effectively totally decarbonised but the mixture of nuclear and renewables is dependent on the individual electricity pathway modelled; here, we assume approximately 
two-thirds of electricity demand is met via nuclear power and the remaining one-third via renewables (in this case existing hydro and a large expansion in offshore wind). Whilst other studies have considered scenarios with high deployment rates of solar energy (e.g., around 50 GWe capacity [11]), the scenarios investigated here assumed high deployment of wind in the context of other published work indicating greater potential for wind energy and the continued high deployment rates of wind energy [5,12].

4. Total GHG emissions in the energy scenario associated with consumption are $160 \mathrm{MtCO}_{2}$ equivalent (eq).

The third key assumption means that, coupled with an assumed load factor of $80 \%$, the total nuclear capacity is approximately 65 GWe. The assumed load factor for the nuclear power plants of $80 \%$ is low by global standards for modern reactors [13]. However, with increasing amounts of variable renewables and a large reactor fleet it is expected that there will be an impact on load factors as reactors will need to vary their output to meet fluctuations in demand and the variable supply from renewables [14]. The 65 GWe nuclear capacity initially comprises (prior to any fast reactor transition) 43 Light Water Reactors (LWRs) constructed over a 25 year period, resulting in a build-rate of around 1.7 reactors per year. Such an increase has an historical precedent with France achieving a maximum build-rate of 3.4 reactors per year [15]. Furthermore, for electricity production, UK policy makers have considered future reactor deployment with capacities between 16 GWe and 75 GWe [1]; hence the 65 GWe is consistent with previous analysis. In all scenarios, the fleet initially consists of LWRs and Advanced Gas-cooled Reactors (AGRs), with all new build systems being of the LWR variety (nominally assumed to be a 33.3\% and 66.7\% split between new build GWe-class BWRs and PWRs, respectively given uncertainties regarding technologies to be adopted in the UK). For comparison, globally around $20 \%$ of LWR fleet is BWR technology [16].

At the present time the UK generates around $20 \%$ of its electricity via nuclear energy, via 7 AGR systems and one PWR (Sizewell B) [12,17]. The UK does not currently meet any of its heat demands directly from nuclear power, apart from indirectly via homes and businesses that employ electrical heating. The UK has previously employed nuclear power for direct heat applications, namely at Sellafield where the Calder Hall power station in Cumbria produced low- and high-pressure steam for the Sellafield site $[18,19]$. Therefore in all scenarios the initial boundary conditions relate to nuclear generating $20 \%$ of electricity and initially providing no direct nuclear process heat. In addition to the currently operating AGR and PWR systems, the UK has historically operated a series of Magnox reactor systems (which included at Calder Hall), which used metallic fuel [20]. In the analyses performed in this study, for those scenarios that employ a closed fuel cycle, the reprocessed spent fuel and associated $\mathrm{Pu}$ from historic operation of the reactor fleet (AGRs, Magnox and Sizewell B) has been used as a stockpile of fissile material, in addition to new fissile material from the expanded LWR fleet modelled in these scenarios.

The total industrial energy (electric and non-electric) demand is based on the high industrial energy demand scenario analysis presented in [5]. The scenario assumes a doubling of industrial energy demand from 2007 levels by 2050 based on an annual industrial growth rate of around 1.5\%, which is similar to the UK's historical industrial growth rate in the 1980s and 1990s [21]. Further information on the industrial energy scenario is presented below in the Section 2.3 and the background on the associated fuel cycle scenarios analysed and why certain metrics have been chosen for analysing fuel cycle performance in Section 2.4.

Based on the above information the corresponding energy demand and breakdown within sectors (industry, transport, heating and lighting \& appliances) are summarised in Figure 1. Figure 1 is a Sankey diagram of the UK energy system in the year 2050. Sankey diagrams represent flows (which broadly could be flows of mass, energy, water or greenhouse gases), with flows represented by arrows or lines, where the thickness of each line represents the amount of flow [22]. Here we are interested in Sankey diagrams describing energy flows, termed energy flow diagrams, which here have units of 
TWh/year [21]. In systems, such as those related to energy, where the flows cannot be lost, the sum of the widths of the lines (the sum of flows) across any section of the diagram, must always be the same.

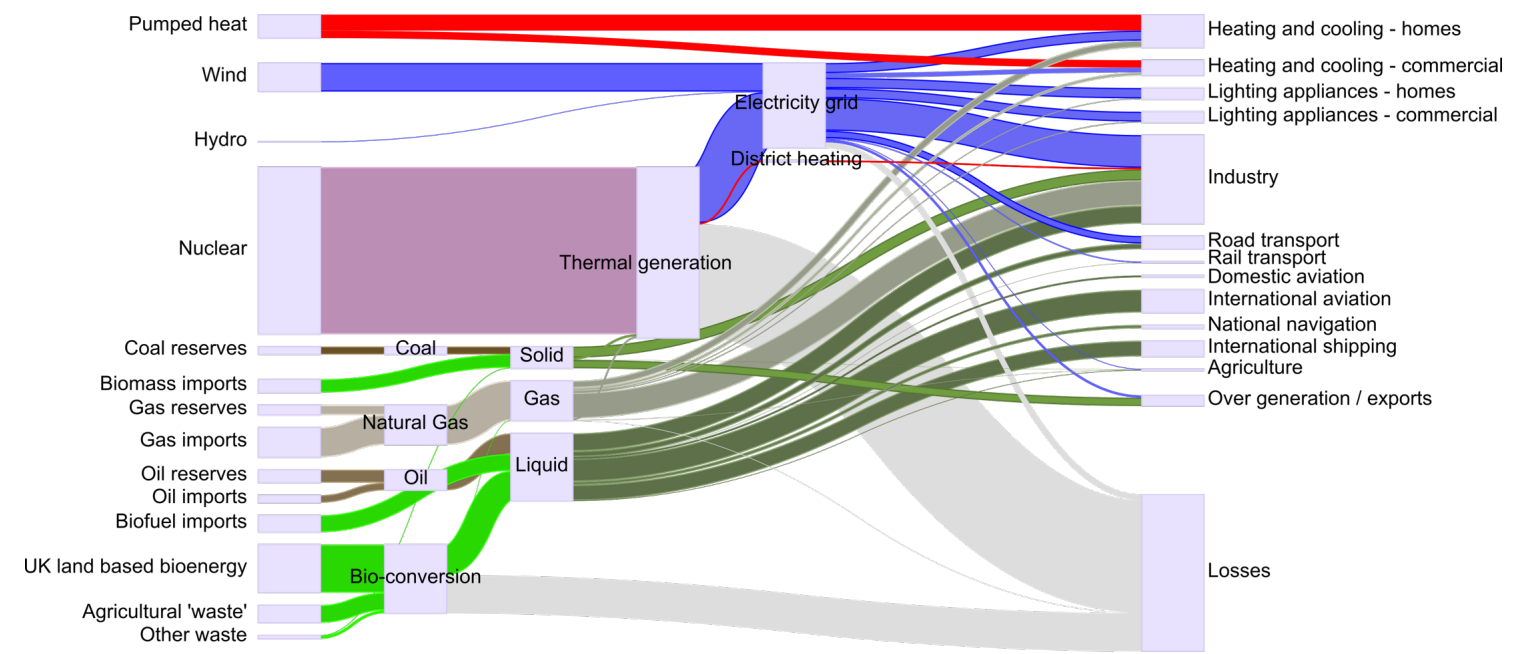

Figure 1. Energy flow diagram for 2050 scenario with high industrial energy demand before utilising nuclear reactors for direct process heat applications [21] (https:/ / bit.ly/2nU7lye).

Figure 1 was generated using the DECC 2050 pathways tool, which can be found at [21]. The DECC 2050 pathway tool nominally assumes non-electric industrial heat is met with fossil fuels or biofuels (with or without carbon capture and storage). Whilst the scenario presented in Figure 1 has net emissions around $160 \mathrm{MtCO}_{2}$ eq, without relying on large-scale deployment of CCS, around $80 \mathrm{MtCO}_{2}$ eq are produced via the combustion of fossil fuels for non-electric industrial energy use. Therefore, any means (such as the application of nuclear power) to limit $\mathrm{CO}_{2}$ emissions from non-electric use in industry, will reduce pressure on other sectors in the economy to decarbonise.

To understand how nuclear power could meet the requirements of industrial process heat it is necessary to first consider the makeup of industrial energy demand. This analysis is summarised in Section 2.2.

\subsection{Industrial Heat Demand}

As a starting point it is important to understand how and where heat is currently used and what role different reactor systems could play before considering changes in future industrial heat demand. From previous work it has been noted [23] that in the literature heat demand is broadly grouped into the following temperature regimes: $<300^{\circ} \mathrm{C} ; 300-500{ }^{\circ} \mathrm{C} ; 500-1000{ }^{\circ} \mathrm{C}$; and $>1000{ }^{\circ} \mathrm{C}$. These temperature regimes are in broad alignment with the working temperatures / outlet temperatures of different types of reactor systems, as summarised in Table 1.

Table 1. Industrial heat demand temperature ranges from the literature and reactor systems, including Liquid Metal Fast Reactors (LMFRs), High Temperature Reactors (HTRs), Very High Temperature Reactors (VHTRs), Molten Salt Reactors (MSRs), Supercritical Water Reactors (SCWRs) and Gas-cooled Fast Reactors (GFRs) capable of operating in the associated temperature ranges [23].

\begin{tabular}{cccccccc}
\hline $\begin{array}{c}\text { Temperature } \\
\text { Range }\end{array}$ & LWRs & LMFRs & HTRs & VHTRs & MSRs & SCWRs & GFRs \\
\hline$<300^{\circ} \mathrm{C}$ & $\checkmark$ & $\checkmark$ & $\checkmark$ & $\checkmark$ & $\checkmark$ & $\checkmark$ & $\checkmark$ \\
\hline $300-500^{\circ} \mathrm{C}$ & $\mathrm{x}$ & $\checkmark$ & $\checkmark$ & $\checkmark$ & $\checkmark$ & $\checkmark$ & $\checkmark$ \\
\hline $500-1000^{\circ} \mathrm{C}$ & $\mathrm{x}$ & $\mathrm{x}$ & $\checkmark^{1}$ & $\checkmark^{2}$ & $\checkmark^{1}$ & $\mathrm{x}$ & $\checkmark^{1}$ \\
\hline$>1000^{\circ} \mathrm{C}$ & $\mathrm{x}$ & $\mathrm{x}$ & $\mathrm{x}$ & $\mathrm{x}$ & $\mathrm{x}$ & $\mathrm{x}$ & $\mathrm{x}$ \\
\hline
\end{tabular}

${ }^{1}$ These systems are capable of operating over only a portion of the prescribed temperature range. ${ }^{2}$ VHTRs currently target temperatures of $1000^{\circ} \mathrm{C}$. 
Using the information in References [24-26] and the assumptions surrounding wider industry outlined in Ref. [23], it is possible to determine breakdowns of non-electric heat demand within the seven industrial categories, see Figure 2. It is important to note that for Coke and refined petroleum; the sector is dominated by energy demand from oil refineries. Oil refineries have temperature demands between 300 to $750{ }^{\circ} \mathrm{C}$, with the bulk of the energy demand at temperatures below $500^{\circ} \mathrm{C}$ [26]. However, there is some uncertainty on the temperature demand between 500 to $750{ }^{\circ} \mathrm{C}$, and uncertainties in heat demand breakdown within wider industry [23], resulting in the error bars which are used to illustrate uncertainties associated with lack of data, indicated in Figure 2. Note that in particular the large uncertainty associated with wider industry is due to lack of data and therefore the large error bars are illustrative. As per Ref. [23], the split in temperature demand, which is known to be dominated by temperatures in the regimes $300-500{ }^{\circ} \mathrm{C}$ and $500-1000{ }^{\circ} \mathrm{C}$, is assumed to be $50 \% 300-500{ }^{\circ} \mathrm{C}$ and $50 \%$ $500-1000{ }^{\circ} \mathrm{C}$.

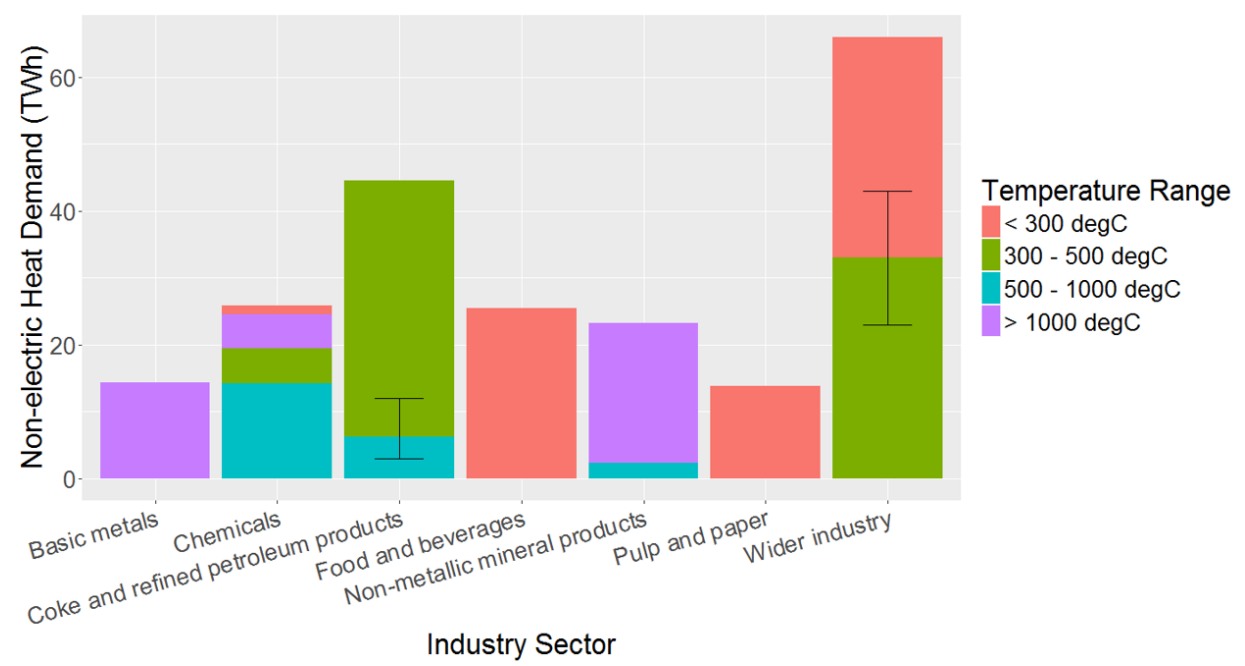

Figure 2. UK heat demand by temperature for non-electrically derived process heat. Error bars indicate uncertainty on the proportion of energy for a particular temperature range [23].

The information presented in Table 1 and Figure 2, indicates that a mixture of small reactors based on HTR, Sodium-cooled Fast Reactor (SFR) and LWR technology would be suitable for meeting around $80 \%$ of current non-electric industrial heat demand, whilst relying on reactor technologies that have all been deployed to at least demonstration scale. For simplicity, in the fuel cycle scenario work presented below, the assumption is that only these three reactor types are deployed for process heat applications and reactors for process heat applications are deployed in increments of 100 MWth units and we have assumed all of the heat from the reactor is available for process heat. In reality it may be the case that only smaller units could be deployed for a small number of industrial sectors and may result in the overall deployment of nuclear power for heat applications being significantly lower. However, there may be the potential for large deployment of industrial clusters where many energy intensive industries are co-located and can access a shared heat source. In addition, it is important to note that transporting high temperature heat to the point of use is more challenging than the transportation of low temperature heat and there may be the need to cluster high temperature heat users together to take advantage of a high temperature heat source $[27,28]$. It is suggested that future work looks in more detail at the feasibility of clustering certain industries together based on heat demand and therefore builds a more detailed model of heat demand taking into consideration heat transport and feasibility of co-location. This may result in significantly lower direct nuclear heat take-up than is assumed in the bounding heat scenario presented in this study. 


\subsection{Industrial Heat Scenarios}

We consider two heat scenarios, using information from [5] with the overall non-electrically derived industrial heat approximately doubling from current demand to around $450 \mathrm{TWh} /$ year by 2050 (see Figure 1). In Scenario 1, we assume the proportions of heat demand from different sectors are approximately the same as they are today but with overall industrial heat demand increasing. This assumption does result in a large proportion of industrial heat demand from oil refineries, whereas most scenarios considered in [5] see significant declines in oil production; however, under some scenarios oil plays a significant role as a feedstock for manufacturing goods, and the central scenarios see emissions from international aviation and shipping doubling, with corresponding demands on oil derived products [8].

Scenario 2 is based on the high industrial energy demand scenario in Ref. [5]. In this scenario, whilst demand for basic metals, non-metallic minerals and chemicals would increase, the rise would be dominated by other industries besides basic metals, non-metallic minerals and chemicals. Furthermore, in much of the scenario analysis presented in [5] oil production substantially declines. To determine the decline in refinery output, the central scenario related to oil refinery outputs in Ref. [29] was employed which forecasts a $1.04 \%$ decline each year. The significant decline in oil production, coupled with the high growth rates in industries other than basic metals, chemicals and non-metallic minerals, implies a larger proportion of heat demand below $500^{\circ} \mathrm{C}$ and electrically derived heat than current levels. The two industrial heat scenarios are summarised in Table 2.

Table 2. Proportion of non-electric heat demand by industrial sector for the two Heat Scenarios considered.

\begin{tabular}{ccc}
\hline Industrial Sector & Scenario 1 & Scenario 2 \\
\hline Basic Metals & $6.51 \%$ & $3.65 \%$ \\
Chemicals & $12.09 \%$ & $10.09 \%$ \\
Coke and refined petroleum products & $20.93 \%$ & $6.44 \%$ \\
Food and beverages & $12.09 \%$ & $17.38 \%$ \\
Non-metallic mineral products & $10.70 \%$ & $8.58 \%$ \\
Pulp and paper & $6.51 \%$ & $9.23 \%$ \\
Wider industry & $31.16 \%$ & $44.64 \%$ \\
\hline
\end{tabular}

Using the information in Table 2, further assumptions are made regarding the suitability of reactor types to the industrial sectors:

- Direct heat from nuclear power plants (NPPs) is not employed in basic metals and non-metallic mineral production due to the fact that they are dominated by temperatures greater than $1000{ }^{\circ} \mathrm{C}$ (see Figure 2).

- Direct heat from NPPs is not employed in the food and beverages sector due to their relatively low heat demand per site and uncertainty surrounding public acceptance of using NPPs to directly supply heat in this industrial sector, as outlined in Ref. [23].

- $\quad$ Oil refineries are unique in their large heat demand ( $\sim 500 \mathrm{MWth})$ per site [26]. It is assumed that only one reactor type is employed (five $100 \mathrm{MWth}$ units) at oil refineries and given the significant but relatively small heat demand above $500{ }^{\circ} \mathrm{C}$ (see Figure 2), we assume HTRs are the preferred reactor technology for supplying low-carbon heat in this sector. This assumption is of limited importance in Scenario 2 but as will be shown is important in Scenario 1 due to the significant demand from oil refineries.

The final set of assumptions, regarding reactor technology deployment rates for the small modular (SM) process heat reactors, assumes SM-PWRs are first deployed in 2025, and SM-HTRs and SM-SFRs are first deployed in 2035. These deployment dates are considered ambitious [30]. Furthermore, it is assumed that HTRs are of the prismatic design type. The nominal build rate that assumes an initial deployment of 2025 for SM-PWR is broadly consistent with recent work [31] that has indicated 
under an optimistic build rate of 3 years and, assuming 5 year licensing, deployment around 2028 . Other scenarios have assumed 5 year build and 5 year licensing periods, resulting in deployment around 2030 [30], and 2035 or later for more advanced reactor designs (e.g., HTR and SFR systems) [30].

\subsection{Fuel Cycle Strategies Considered}

The reactor technologies and fuel cycle adopted in the future will depend on several potential influencing factors, including:

1. Cost.

2. The specific demand (e.g., electricity, high temperature process heat, low temperature process heat, etc).

3. Uranium availability.

4. Minimising spent fuel storage.

5. Minimising the impact or potentially simplifying the licensing for a geological disposal facility by reducing thermal heat load and radiological impact.

It should be noted that it is impossible to know precisely which of these drivers will become important enough to influence the UK's nuclear fuel cycle. In the authors opinion it is judged that if the UK developed nuclear power to the levels necessary to curtail greenhouse gas emissions and reduce the impact of global warming, several other countries would most likely follow this approach. This would apply greater pressure on existing and future natural uranium reserves. In such a future, it is possible that there will be a need to recycle fissile material in a closed fuel cycle. In the interim period, prior to operating a closed fuel cycle, there may still be a driver to reprocess and recycle fissile material as Mixed Oxide (MOX) Fuel in a thermal (LWR) system, as a way of managing future spent fuel stockpiles, as is the approach in France.

Three potential future fuel cycle strategies have been assessed, assuming varying degrees of future uranium availability, these are:

(A) Natural uranium becomes sufficiently scarce such that a closed fuel cycle is ultimately required at the earliest opportunity.

(B) Natural uranium becomes sufficiently scarce but at a date which still allows maximum LWR-MOX utilisation in the interim period prior to a transition to a fast reactor fuel cycle.

(C) Natural uranium is plentiful and there is little need to reduce the amount spent fuel stored (e.g., it is socially acceptable to store spent fuel long term or repositories are sequentially commissioned over the next 200 years).

In implementing the three potential fuel cycle strategies, fuel cycles A and B assume an initial '1st' generation LWR fleet transitioning to a fast reactor fuel cycle. In scenario A, the transition takes place as soon as possible, whereas scenario B assumes LWR-MOX utilisation is allowed in the interim period in order to reduce the spent fuel stockpile to current levels. Scenarios A and B assume that for process heat application, a mixture of small modular MOX fuelled fast reactors (FRs), $\mathrm{UO}_{2}$ fuelled LWRs and $\mathrm{UO}_{2}$ fuelled HTRs are initially operated, with a gradual phase out of the SM-LWR fleet to be replaced by additional SM-FR units. The SM-HTRs continue to operate due to their ability to achieve higher temperatures than SM-SFRs; however, there will be an impact on uranium consumption, which is captured in the ORION analysis, since HTR fuel cannot realistically be recycled due to the nature of the fuel form which makes it difficult to separate out the fissile material from its surrounding materials. Scenario $C$ assumes no application of FRs except for heat applications and no phase out of the SM-LWR fleet as a result of the assumption regarding future uranium availability. Given the two heat scenarios (1 and 2) and the three fuel cycle strategies (A, B and C), this results in six scenarios assessed, see Section 3.

Note that previous work [1] has been undertaken to assess the potential of early deployment of SFRs to close the fuel cycle. The work presented in Ref. [1] showed that there were minimal benefits 
relative to scenarios where an LWR fleet preceded the SFR fleet. Therefore, scenarios above involving deployment of SFRs outside of heat applications, first deploy GWe-class LWRs, which given the technical maturity of LWR technology it is reasonable to assume a large reliance on LWR technology in the short to medium-term.

A final key assumption when modelling the fuel cycle strategies relates to when to halt operation of the reactors, for instance due to an alternative energy technology being developed that supersedes the systems under consideration or the implementation of policies to move away from a particular energy technology. Here, the boundary condition for the scenarios assume all reactors cease operation 300 years after first criticality of the UK's first nuclear power plant, i.e. operation of reactors ends in the year 2255. When looking at future scenarios, particularly those related to closing the fuel cycle and utilising spent fuel it is important to consider longer term strategies than 80 years. Typically benefits of closed fuel cycles are considered under nuclear energy scenarios spanning timescales around 200 to 300 years [32,33]. Therefore, if the intention was to only build one lot of reactor systems for 80 years and then completely halt the use of nuclear energy, it is very unlikely a closed fuel cycle would be considered.

In the analysis presented here, the ORION fuel cycle code has been used to model the scenarios detailed earlier. ORION is capable of tracking in detail around 2500 nuclides (encompassing both short lived and long lived nuclides), and can model decay and in-reactor irradiation [1]. Hence, ORION can determine important characteristics of any fuel cycle, including the availability of bred fissile material (e.g., $\mathrm{Pu}$ ); the quantity of spent fuel or reprocessed waste streams, along with the associated decay heat and radiotoxicity; and the natural uranium demands.

Based on the reactor technologies considered, their assumed power densities and dwell time (the length of time the fuel resides in the core) the burnup levels for the different reactor types are summarised in Table 3.

Table 3. Average discharge burnup for each reactor type considered in the scenarios modelled.

\begin{tabular}{cc}
\hline Reactor Type & Average Discharge Burnup \\
\hline SM-PWR & $40 \mathrm{GWd} / \mathrm{tHM}$ \\
SM-HTR & $80 \mathrm{GWd} / \mathrm{tHM}$ \\
SM-SFR & $105 \mathrm{GWd} / \mathrm{tHM}$ \\
SFR & $105 \mathrm{GWd} / \mathrm{tHM}$ \\
BWR & $45 \mathrm{GWd} / \mathrm{tHM}$ \\
PWR & $50 \mathrm{GWd} / \mathrm{tHM}$ \\
\hline
\end{tabular}

The small modular reactors for industrial heat applications were assumed to operate with high load factors of around $90 \%$, due to the fairly constant industrial heat demand they service [23], with dwell times of around 5 years. The exception to this was the SM-SFR which was assumed to achieve the same discharge burnup as the large SFR by operating at a higher load factor than the SFR fleet ( $90 \%$ vs $80 \%$ ) but with a corresponding lower power density [34]. The large reactors (SFR, BWR and PWR) all had assumed load factors of around $80 \%$ since the operation of large fleet of nuclear power plants in the model would likely result in the need for flexible power operation [21]. The disparity in discharge burnup for the SM-PWR ( $40 \mathrm{GWd} / \mathrm{tHM})$ vs the large PWR ( $50 \mathrm{GWd} / \mathrm{tHM}$ ) was predominantly due to the low power density assumed for the SM-PWR (around $66 \%$ that of the large PWR) and 5 year dwell time [35-38].

\section{Results and Discussion}

The focus of this study is on: Pu management; natural uranium demands; spent fuel; and thermal repository demands associated with the decay heat from the spent fuel or reprocessed waste streams. Radiotoxicity has not been investigated since it is generally not limiting from a repository design perspective, this is because radiotoxicity in the long-term is dominated by plutonium and the minor actinides $[39,40]$. However, these actinide species exhibit low mobility under repository 
conditions [40-42], whereas the decay heat from the material considered waste may be more limiting depending on geological conditions, ultimately governing repository size.

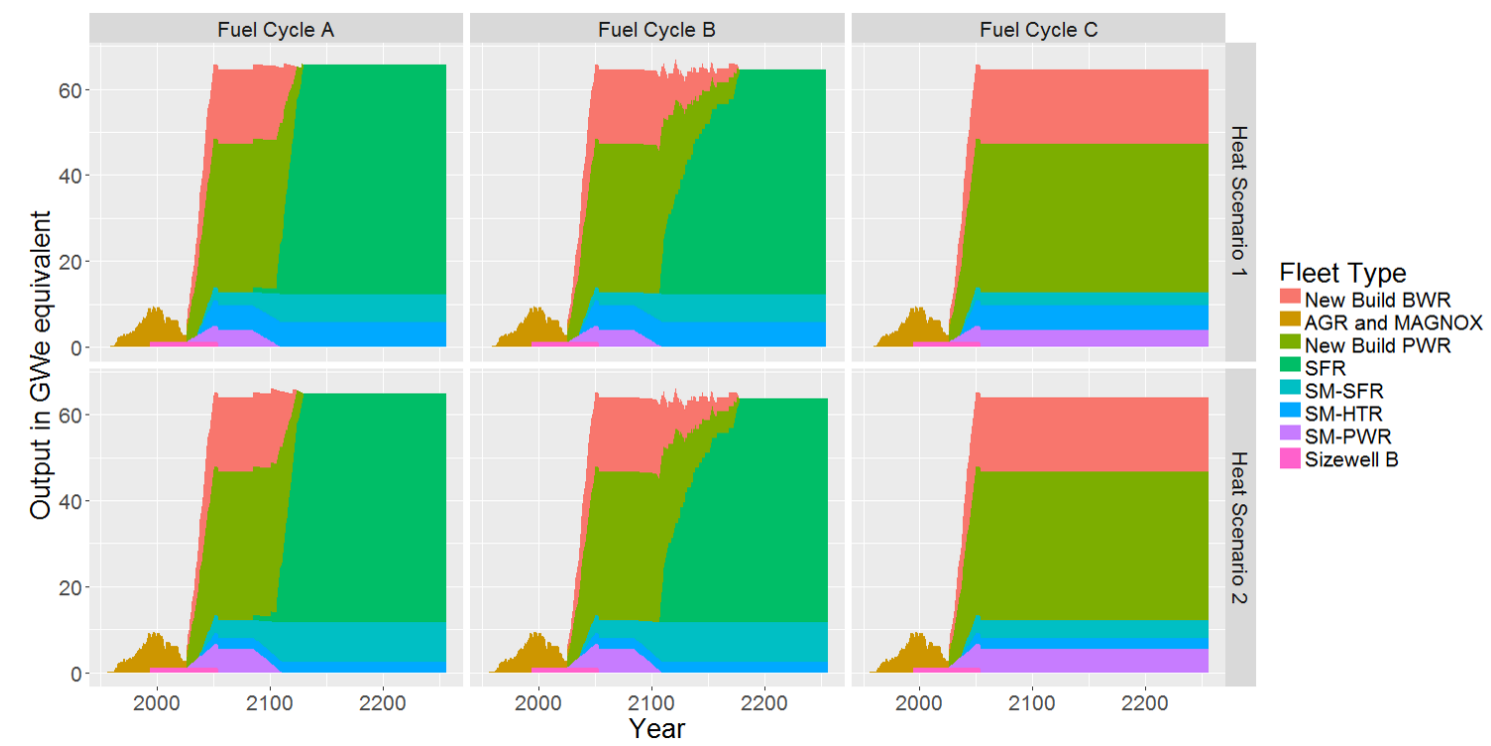

Figure 3. Deployment rates of different reactor technologies for the three fuel cycle strategies and two heat scenarios, resulting in a total of six scenarios.

Noting that, as outlined in Section 2.3, two heat scenarios are modelled and as outlined in Section 2.4 three fuel cycle strategies are considered, this results in a total of six scenarios modelled using the ORION fuel cycle code, see Figure 3. The vertical axis in Figure 3 is in terms of GWe, with the smaller process heat systems converted to equivalent electric outputs using $40 \%, 33.3 \%$ and $31 \%$ for thermal efficiencies of SM-HTRs, SM-SFRs and SM-PWRs, respectively.

\subsection{Plutonium Management and Uranium Availability}

For scenarios transitioning to a fast reactor fuel cycle (Scenarios A and B), Pu availability is vitally important and dictates the time at which a transition could potentially occur. A significant amount of $\mathrm{Pu}$ is necessary for this transition, which will primarily originate from the reprocessing of LWR spent fuel. In the case of scenario A, where it is assumed that limited LWR-MOX utilisation takes place, it will be possible to fully transition by 2125-2150, as shown in Figure 3. However, this does assume the 1st generation LWR fleet can operate for 80 years, without which there would be insufficient $\mathrm{Pu}$ available for a full transition. Furthermore, this calculation assumes the fast reactor fuel cycle will operate with fuel that has been cooled for 4 years prior to reprocessing, with a further 2 years to account for the time it takes to reprocess the spent fuel, manufacture the MOX fuel and transport back to the reactor site. Scenario B assumes significant LWR-MOX utilisation (peaking at $180 \mathrm{tMOX/year} \mathrm{beyond} \mathrm{2050).}$ The reduction in both quantity and quality of the potential Pu stockpile results in a delay of 50 years before a full transition can occur, as shown in Figure 3.

As a large stockpile of $\mathrm{Pu}$ is necessary (which will have to be bred beforehand using a thermal reactor fleet), the total amount of natural uranium required for a self-sustaining fast reactor fleet is approximately $1.2 \mathrm{Mt}$ by 2110 . This amount is equivalent to all identified, reasonably assured and inferred resources in the lowest cost category ( $<$ USD 40 $/ \mathrm{kgU}$ ) according to IAEA as of 2016 [43]. Although the estimates quoted are very uncertain and will likely increase with a rising uranium ore price, the UK is a relatively small country and one of several countries who could adopt nuclear power to reduce GHG emissions. The amount required is therefore still extremely high and will place significant demand on future supply. 
For Group B scenarios, the amount of uranium ore required is also $1.2 \mathrm{Mt}$, although at a slightly later date of 2170 coinciding with the later full transition date. For an equivalent open fuel cycle, between 2-2.5 Mt of natural uranium is required by the same date.

\subsection{Spent Fuel Management}

For Group A scenarios, $\mathrm{Pu}$ is not required until the fast reactor fleet commences operation. Consequently, the amount of spent fuel accumulates to 70,000-80,000 tHM once the need for reprocessing is realised. For Group B scenarios, $\mathrm{LWR}-\mathrm{UO}_{2}$ spent fuel reprocessing and a significant increase in LWR-MOX fuel fabrication begins in 2050, reducing peak spent fuel accumulation to approximately 30,000 tHM. During the transition period, the spent fuel produced by the dedicated process heat nuclear plants is very small compared to the large quantities produced for electricity production. Recycling the $\mathrm{Pu}$ from $\mathrm{LWR} \mathrm{UO}_{2}$ spent fuel as LWR MOX fuel allows a country to store the Pu required to eventually start a closed fuel cycle in a more compact form whilst ensuring the fissile material is being actively used and in a form that is more proliferation resistant. It is also the policy that has been adopted by France since the 1980s to manage their spent fuel stockpile in anticipation of a future transition to a fast reactor based fuel cycle. However, once the existing spent fuel stockpiles deplete (coinciding with a complete fast reactor transition), the continuous production of HTR fuel and an excess amount of fast reactor spent fuel accumulating becomes more apparent as shown in Figure 4 .

Figure 4 illustrates the transition from an unsustainable (ever increasing demands on geological disposal facilities) open fuel cycle to sustainable closed fuel cycles, where demands on geological disposal facilities are much lower, with the slight positive gradient associated with the use of open-cycle HTRs for industrial heat and SFRs with a breeding ratio of 1.08 to allow for a Pu contingency to be acquired in the event of a supply disruption (for e.g., a fault at the reprocessing or MOX fabrication facilities).

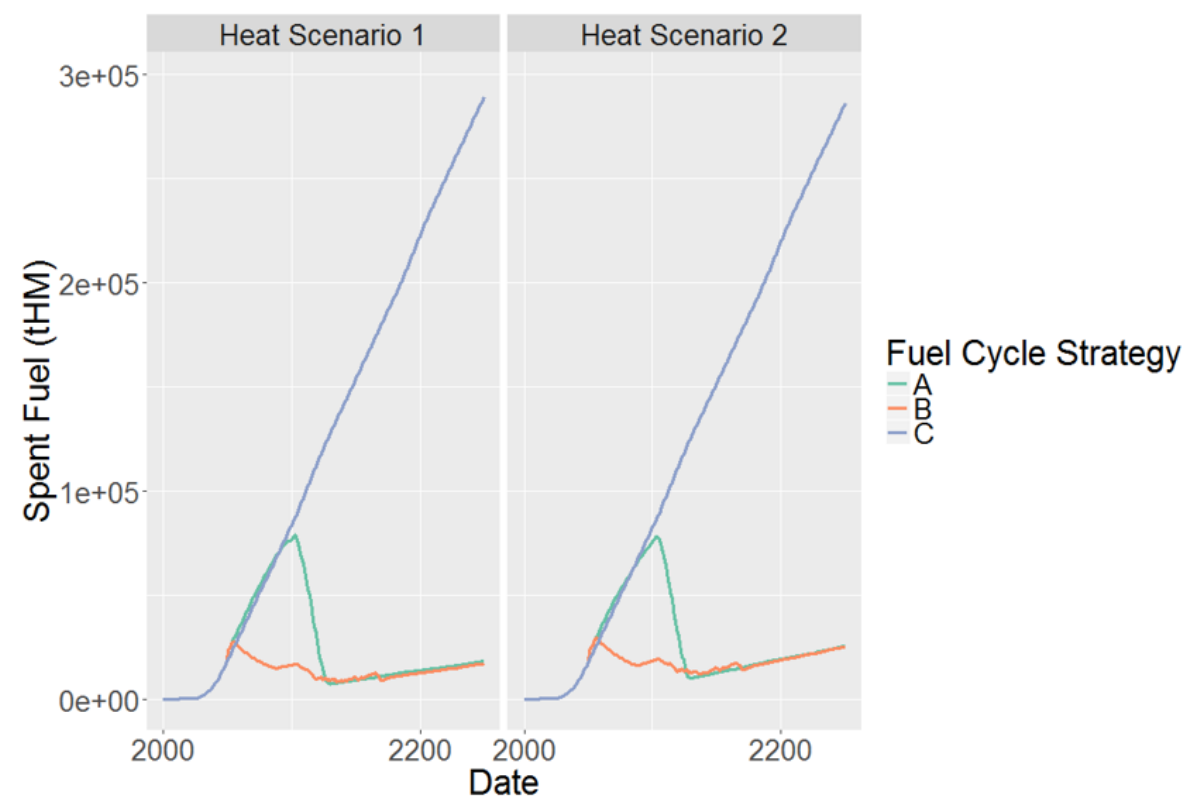

Figure 4. Masses of spent fuel for the different scenarios investigated.

Besides spent fuel mass (tHM) it is important to consider the volumes of spent fuel. The volumes of spent fuel will vary depending on the reactor technology employed. In the case of waste produced from prismatic HTRs the key parameters for determining volume of spent fuel waste per tHM are [44,45]: particle packing fraction (0.3); $\mathrm{UO}_{2}$ kernel radius $(0.025 \mathrm{~cm})$; kernel density $\left(10.82 \mathrm{~g} / \mathrm{cm}^{3}\right)$; particle radius $(0.045 \mathrm{~cm})$; fuel block height $(80 \mathrm{~cm})$; hexagonal pitch $(36 \mathrm{~cm})$; fuel pins per fuel block (210); and radius of fuel compact $(0.635 \mathrm{~cm})$. This results in $8.6 \mathrm{~m}^{3} / \mathrm{tHM}$ of spent fuel waste. 
However, there is precedent for consolidation of HTR waste forms, as per the Dragon reactor [46]. The degree of waste consolidation would need to be subject to a separate study, nevertheless it is possible to determine the upper limits on waste consolidation when assuming fuel compact volumes will ultimately limit the extent of waste consolidation. Taking this into account, the fuel from up to 3.8 fuel blocks could theoretically occupy the same volume as one fuel block, which results in $2.3 \mathrm{~m}^{3} / \mathrm{tHM}$ of spent fuel waste. In the event waste consolidation is chosen, then it is likely that the volume of spent fuel will be between $2.3-8.6 \mathrm{~m}^{3} / \mathrm{tHM}$. Therefore, we assume the average between these two values of $5.5 \mathrm{~m}^{3} / \mathrm{tHM}$ in our analysis.

For the volume of spent fuel per tHM from the SFR fleet the key parameters are [34,47-49]: the pins per assembly (331); active fuel height $(1 \mathrm{~m})$; fuel outer radius $(0.4225 \mathrm{~cm})$; MOX fuel density $\left(10.3 \mathrm{~g} / \mathrm{cm}^{3}\right)$; and hexagonal pitch $(21.28 \mathrm{~cm})$. The fuel assembly total height including assembly foots, heads and integral reflector is assumed to be $4 \mathrm{~m}$. This results in a volume of spent fuel waste of $0.93 \mathrm{~m}^{3} / \mathrm{tHM}$. This same factor is applied to spent fuel volumes from the SM-SFR fleet.

The volume of spent fuel from the PWR fleet is calculated on the basis of [50,51]: assembly height $(4.2 \mathrm{~m})$; pins per assembly (264); outer radius $(0.4096 \mathrm{~cm})$; active fuel height $(3.65 \mathrm{~m})$; fuel density $\left(10.5 \mathrm{~g} / \mathrm{cm}^{3}\right)$; and assembly pitch $(21.5 \mathrm{~cm})$. This results in a volume of spent fuel waste of $0.41 \mathrm{~m}^{3} / \mathrm{tHM}$. This same factor is applied to spent fuel volumes from the SM-PWR fleet. A similar calculation for the BWR spent fuel mass [52,53] (noting the assembly height is $4.5 \mathrm{~m}$, there are 92 fuel rods per assembly, the assembly pitch is $15.5 \mathrm{~cm}$ and the fuel rod outer radius is $0.438 \mathrm{~cm}$, with an active height of $3.81 \mathrm{~cm}$ ) gives a spent fuel volume of $0.55 \mathrm{~m}^{3} / \mathrm{tHM}$.

Using the conversion factors from spent fuel masses to volumes for: LWR technology (BWR and PWR systems); HTR systems; and the large and small modular variants of SFRs investigated, it is possible to consider the volumes of spent fuel from the new build systems, see Figure 5. The scenarios with a focus on fast reactor systems (i.e., fuel cycle strategy A with heat scenarios 1 and 2 (A1 and A2) and fuel cycle strategy with heat scenarios 1 and 2 (B1 and B2)) operating on a closed fuel cycle (around 60 GWe equivalent) and a relatively small uptake of HTRs (up to around 15 GWth) operating on a once-through cycle, have smaller volumes of spent fuel; however, even though the HTR fleet is modest in comparison with the fast fleet, they dominate the spent fuel volumes. The volumes of waste associated with the fast reactor fleet in scenarios A1, A2, B1 and B2 relate to the volumes of waste associated with the final cores once the decision is taken to halt fast reactor operation. Volumes of spent fuel are larger with the scenario employing systems operating entirely on a once-through fuel cycle; however, the relatively compact LWR spent fuel volumes associated with LWR technology, result in total volumes being roughly double those of scenarios A and B, even though total spent fuel masses are far higher (see Figure 4).

The volumes of Vitrified High Level Waste (VHLW) in Figure 5 are based on each VHLW canister being 169 litres, and containing approximately $400 \mathrm{~kg}$ of glass of which $25 \mathrm{wt} \%$ is fission product oxide [54]. It is important to note that there is considerable uncertainty on the achievable incorporation rates for reprocessed MOX fuel and for high burnup fuel of the type in the SFR fleet. We have assumed that the $25 \mathrm{wt} \%$ fission product historically achieved with reprocessed fuel [54] can be achieved for SFR fuel. Finally, as can been seen in Figure 5, the total spent fuel and VHLW volumes are similar for scenarios A and B since both scenarios are ultimately closed fuel cycles with scenario B only delaying the introduction of the LWR spent fuel to the SFR fleet. This is because scenario B (which employs MOX fuel in LWRs) is an interim solution to manage LWR spent fuel in the medium-term whilst using well-established LWR technology. 


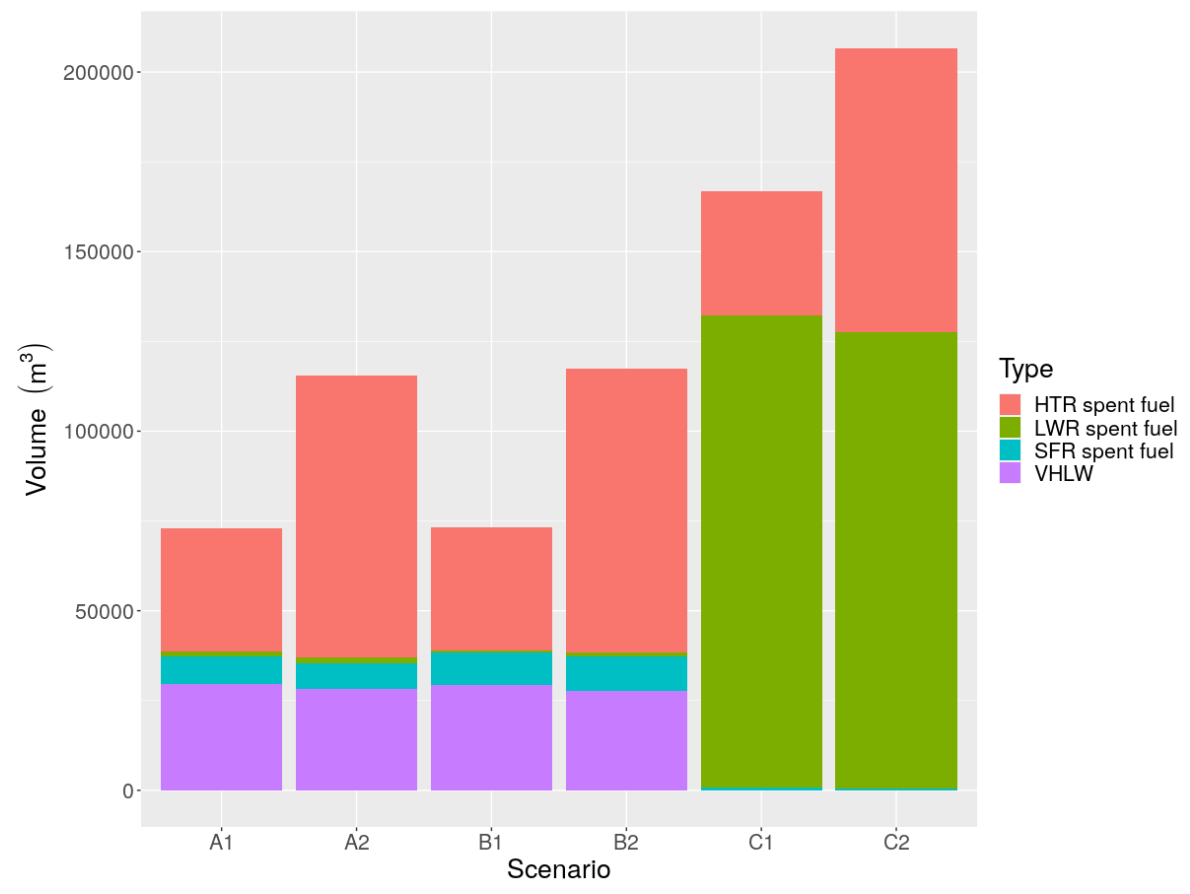

Figure 5. Volumes of spent fuel and Vitrified High Level Waste (VHLW) in year 2255 for the three fuel cycle strategies (A, B and C) and two heat scenarios (1 and 2), which results in six total scenarios.

\subsection{Thermal Implications on the Repository}

Figure 6 shows the total decay heat sent to repository for all scenarios considered, assuming 100 years interim storage for all material considered waste. When studying the thermal implications on the repository two reprocessing strategies have been modelled for each of the three fuel cycle strategies:

(A) a nominal case assuming minimal minor actinde (Am) recycling during the scenario. The only Am recycled through the fast reactor fleet originates from fast reactor spent fuel. Any Am present in LWR fuel is immobilised and disposed of along with the fission product inventory. The reason for focusing on Am is because of the important role Am plays in decay heat output for the timescale considered [55].

(B) a more challenging scenario assuming maximum minor actinide (Am) recycling throughout. All Am from fuel to be reprocessed and recycled as fast reactor MOX fuel is separated and recycled along with the Pu as MOX fuel. The only Am that is not recycled is from fuel that is reprocessed for use in the LWR fleet.

As shown in Figure 6, for Group B scenarios, the prolonged use of LWR-MOX fuel during the transition to fast reactors and the inability to recycle Am in significant quantities through an LWR, results in a large change in decay heat output, as is evident in the step-change from 2150 onwards. In a thermal system, Am tends to build up relatively quickly and since LWR are required during the short to medium term, the Am inventory in the LWR spent fuel is significant. Eventually, the significant increase in decay heat saturates as the transition to fast reactors is made.

For scenarios with minimal Am recycle (i.e., only Am separated from fast reactor MOX fuel is recycled), a further deviation occurs around 2200 once the fast reactor fleet commences operation. As most of the Pu required to initiate the fast reactor fuel cycle is sourced from either $\mathrm{LWR}^{-\mathrm{UO}_{2}}$ or LWR-MOX spent fuel (both of which will contain approximately $15 \mathrm{wt} . \%$ Am after 30 years cooling), treating this element as waste will significantly increase the decay heat in the repository. 


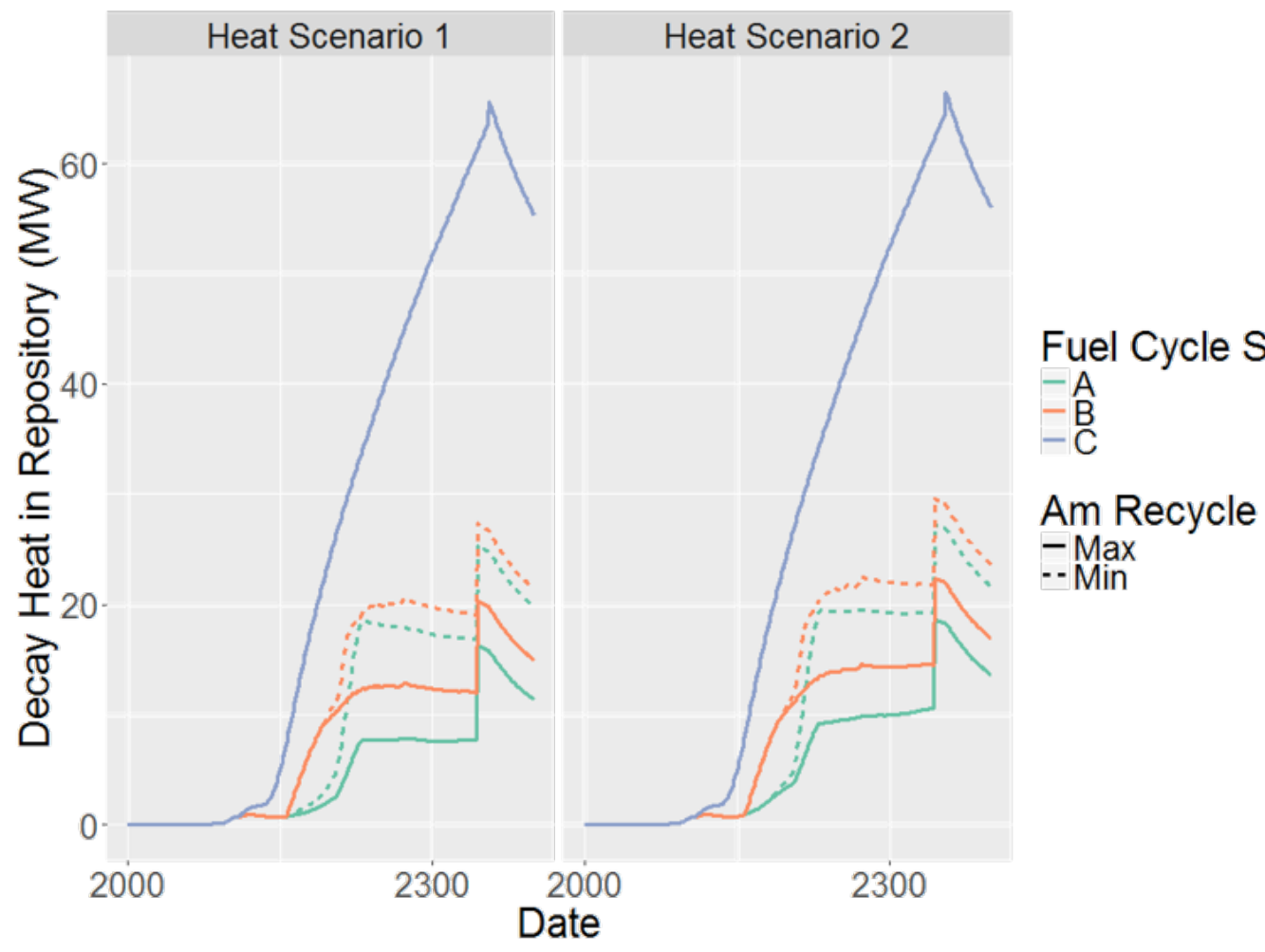

Figure 6. Cumulative decay heat, with decay heat from final cores considered.

Figure 6 also includes an estimate for the final cores assuming these are cooled for 100 years after the end of the scenario and sent for geological disposal. The increase for the open fuel cycles is relatively small, especially when compared to the amount produced beforehand. This is because the spent $\mathrm{UO}_{2}$ spent fuel discharged will have a relatively low $\mathrm{Pu}$ and minor actinide content (when compared to fast reactor fuel). For the fast reactor fuel cycles, the increase is more noticeable, as a result of the significant quantities of $\mathrm{Pu}$ and $\mathrm{Am}$ in the spent MOX fuel entering the repository.

\section{Pathways to Further Reduction in GHG Emissions}

The scenario in Figure 1 has net emissions around $160 \mathrm{MtCO}_{2} \mathrm{eq} / \mathrm{yr}$, which equates to an $80 \%$ reduction in UK GHG emissions from 1990 levels. The use of nuclear energy in industry to displace fossil fuels in the base scenario outlined in Figure 1 could further reduce GHG emissions by around $60 \mathrm{MtCO}_{2} \mathrm{eq} / \mathrm{yr}$, whilst assuming bioenergy is employed for meeting heat demand in food production industrial sector and for very high temperature heat $\left(>1000{ }^{\circ} \mathrm{C}\right)$. Further reductions in emissions from the scenario in Figure 1 would be possible via the technologies summarised in Table 4 .

Table 4. Levels of emission reduction achievable by additional technologies over central scenario in Figure 1.

\begin{tabular}{cc}
\hline Technology & Corresponding GHG Emission Reduction \\
\hline $\begin{array}{c}\text { Deployment of low-carbon } \mathrm{H}_{2} \text { to displace } 85 \mathrm{TWh} / \mathrm{yr} \text { of } \\
\text { natural gas in residential and commercial heating }\end{array}$ & $16 \mathrm{MtCO}_{2}$ eq/yr \\
\hline $\begin{array}{c}\text { Displace } 48 \mathrm{TWh} / \mathrm{yr} \text { of oil demand with } \\
\text { low-carbon } \mathrm{H}_{2} \text { in hard to reach road transport sectors }\end{array}$ & $12 \mathrm{MtCO}_{2} \mathrm{eq} / \mathrm{yr}$ \\
\hline Greenhouse gas removal technologies & $32 \mathrm{MtCO}_{2} \mathrm{eq} / \mathrm{yr}$ \\
\hline $\begin{array}{c}\text { Greater deployment of CCS for industrial } \\
\text { process emissions }\end{array}$ & $6 \mathrm{MtCO}_{2} \mathrm{eq} / \mathrm{yr}$ \\
\hline
\end{tabular}


The scenario summarised in Figure 1 has only a small role for CCS. There is the potential to use CCS technology for the removal of greenhouse gases from the atmosphere to further reduce emissions and achieve net zero. The range of scenarios with significant contributions from greenhouse gas removal considered in the UK for GHG removal is $32 \mathrm{MtCO}_{2}$ eq/yr to $130 \mathrm{MtCO}_{2}$ eq/yr [56]. However, the upper range should be considered very speculative and relies heavily on Bioenergy with Carbon Capture and Storage (BECCS) and Direct Air Capture of $\mathrm{CO}_{2}$ with Storage (DACCS) [57]. Therefore, whilst it may be possible to achieve Net Zero GHG emissions by employing Greenhouse Gas Removal (GGR) technologies, it would be prudent to assume only $32 \mathrm{MtCO}_{2} \mathrm{eq} / \mathrm{yr}$ of CCS for the purpose of atmospheric GHG removal is available, as summarised in Table 4.

The large role of industrial demand in the scenario summarised in Figure 1 results in industrial process emissions of around $35 \mathrm{MtCO}_{2} \mathrm{eq} / \mathrm{yr}$, with around $12 \mathrm{MtCO}_{2} \mathrm{eq} / \mathrm{yr}$ captured via CCS. Ref. [5] notes that potentially up to $48 \%$ of industrial process emissions could be realistically captured, which results in $18 \mathrm{MtCO}_{2}$ eq/yr captured (i.e., a reduction in $\mathrm{GHG}$ emissions of $6 \mathrm{MtCO}_{2} \mathrm{eq} / \mathrm{yr}$ over the reference scenario in Figure 1). This additional deploymet of CCS for industrial process emissions is also captured in Table 4. Hence, the additional assumptions related to greater adoption of CCS, GGR and the deployment of low-carbon hydrogen, results in net GHG emissions of $34 \mathrm{MtCO}_{2} \mathrm{eq} / \mathrm{yr}$. Net emissions of $34 \mathrm{MtCO}_{2}$ eq/yr equates to a reduction in $\mathrm{GHG}$ emissions by around $96 \%$ relative to 1990 levels in the UK. However, this assumes a very large role for nuclear energy in electricity and industrial sectors, a significant expansion of bioenergy consumption (around $650 \mathrm{TWh} / \mathrm{yr}$ ) in addition to $50 \mathrm{MtCO}_{2} \mathrm{eq} / \mathrm{yr}$ of CCS and GGR (currently the UK captures $0 \mathrm{MtCO}_{2} \mathrm{eq} / \mathrm{yr}$ ) and $133 \mathrm{TWh} / \mathrm{yr}$ of low-carbon hydrogen production. For comparison, the UK currently produces around $27 \mathrm{TWh} / \mathrm{yr}$ of carbon intensive hydrogen [58].

To put the $133 \mathrm{TWh} / \mathrm{yr}$ of hydrogen production in to context, for this amount of hydrogen to be produced via thermo-chemical cycles using high temperature nuclear heat [23], e.g., from High Temperature Reactors (HTRs), this would require around $33 \mathrm{GWth}$ of HTR capacity operating with an Iodine-Sulphur (I-S) cycle with an assumed efficiency of 45\% [59]. For comparison, the analysis in Section 3 considered up to around 15 GWth HTR deployment. Nevertheless, based on the previous analysis but with up to 33 GWth of HTR usage, the spent fuel and repository impact of HTR deployment for hydrogen usage with around $133 \mathrm{TWh} / \mathrm{yr}$ of hydrogen would be significant but result in additional waste volumes comparable to those studied in this investigation. However, it should be noted that UK scenarios with around 700 TWh of hydrogen production have also been considered [56,58], which would potentially result in around 175 GWth of HTR deployment solely for hydrogen production. Under a scenario of around 175 GWth of additional HTR deployment the repository and spent fuel impact would need to be carefully considered. Hence, in scenarios with a large reliance on high temperature heat but pressures related to uranium scarcity and/or spent fuel management concerns it would be prudent in future work to consider alternative Gen-IV systems capable of operating at higher outlet temperatures (for instance Molten Salt Reactors) [60,61]. One other area of future work would be how best to utilise, given the challenges in reprocessing HTR fuel, the once-through HTR fleet besides replacement of the HTR fleet with reactor systems capable of achieving high temperatures and operating with a closed fuel cycle. One option would be the utilisation of a thorium-plutonium HTR [62-65], which show improved conversion ratios (0.60-0.65 [66]) relative to LEU fuelled HTRs (around 0.5 [45]); however noting that whilst this will initially place lower demands on natural uranium demand it will result in plutonium no longer being readily accessible for later use in the SFR fleet.

\section{Summary and Conclusions}

In this investigation, we have demonstrated the use of Energy Flow (Sankey) diagrams to capture the demands on low-carbon energy and then used this information to construct a bounding case relating to high industrial energy demand, with only moderate levels of electrification of industrial 
heat demand. Thereby allowing for direct (non-electric) applications of nuclear process heat on the fuel cycle to be considered, with the fuel cycle analysis performed using ORION.

The central scenario that is the focus of this study has high industry energy demand with a large role for nuclear power in both residential/commercial electricity and industrial heat demand, and significant bioenergy production. However, in this central scenario there is a limited role for Carbon Capture and Storage (CCS) and hydrogen, which results in UK emissions reducing by around $87 \%$ relative to 1990 levels. Based on this central scenario three distinct fuel cycle strategies are analysed: (A) a transition to a closed fuel cycle as quickly as possible; (B) a transition to a closed fuel cycle but with interim use of LWR-MOX; and (C) an open fuel cycle, with two heat demand scenarios analysed to take account for different profiles in temperature demand dependent on the types of industry that dominate industrial demand by the year 2050. Other scenarios are briefly outlined to achieve greater GHG reductions, highlighting the potential for an expansion of nuclear power to produce low-carbon hydrogen and more extensive adoption of CCS and the use Greenhouse Gas Removal (GGR) technologies to reduce emissions by around 96\% relative to 1990 levels.

The scenario analysis performed here has focused on three reactor technologies (LWRs, SFRs and HTRs) that have all been deployed to at least the demonstration scale and are able to meet around $80 \%$ of non-electric industrial heat demand. The two heat scenarios modelled, based on high industrial energy demand but different requirements from particular industries, constituted two bounding cases regarding the role the three reactor technologies could play in decarbonising future UK industry demands. It was found that the overall deployment rate for HTR systems is highly sensitive to the assumption that HTRs are the preferred technology to decarbonise heat demand at oil refineries. The large-scale deployment of direct nuclear process heat for industrial customers reduced annual $\mathrm{CO}_{2}$ emissions by around $60 \mathrm{MtCO}_{2}$ eq via the displacement of fossil fuels, relative to the base scenario with net $\mathrm{GHG}$ emissions of $160 \mathrm{MtCO}_{2}$ eq.

Under the high industrial heat scenarios modelled, the analysis with ORION showed that should the need for a closed fuel cycle arise in the future using SFR technology, a transition by 2130 is possible, so long as: the fast reactor fleet is preceded by a similar sized LWR fleet; LWR-MOX utilisation is limited; and the LWR units are able to operate 20 years beyond the nominal 60 year lifetime. If LWR-MOX fuel is used extensively, the quality and quantity of the potential Pu available for the fast reactor fleet will be degraded, resulting in a delay of approximately 50 years before a full transition is complete. The scenarios pertaining to fuel cycle strategies A and B were found to place significantly lower demands on spent fuel mass and decay heat output, compared with the ever-increasing demands from the scenario deploying only open-cycle reactor systems (Scenario C). Furthermore, in Scenarios A and $\mathrm{B}$, even though the HTR fleet is modest in comparison with the fast fleet, the HTRs systems dominate the spent fuel volumes.

Finally, this is first time in the UK when nuclear fuel cycle scenarios have been developed that take account of nuclear heat applications. Furthermore, even in high industrial energy demand scenarios, the sensitivity of spent fuel masses and decay heat to the types of reactor deployed is relatively small compared to the greater fuel cycle demands from large-scale deployment of nuclear plants for electricity production. However, the sensitivity of spent fuel volumes depends heavily on the extent to which High Temperature Reactor systems and Light Water Reactor once-through cycle are deployed. Therefore, in the event there is large-scale deployment of nuclear heat for hydrogen production from HTR systems the impact on waste volumes would need to be carefully considered.

Author Contributions: Conceptualization, A.P.; methodology, A.P.; software, A.P. and R.G.; validation, A.P. and R.G.; formal analysis, A.P.; investigation, A.P. and R.G.; resources, A.P.; data curation, A.P. and R.G.; writing-original draft preparation, A.P.; writing-review and editing, A.P. and R.G.; visualization, A.P.; supervision, A.P.; project administration, A.P.; funding acquisition, A.P. All authors have read and agreed to the published version of the manuscript.

Funding: This research was funded by the UK government's Department for Business, Energy and Industrial Strategy, as part of the Nuclear Innovation Programme (Nuclear Facilities and Developing a Strategic Toolkit) grant number 13070002346 . 
Acknowledgments: The authors would like to gratefully acknowledge input received from Kevin Hesketh (NNL) and Bruno Merk (University of Liverpool).

Conflicts of Interest: The authors declare no conflict of interest. The funders had no role in the design of the study; in the collection, analyses, or interpretation of data; in the writing of the manuscript, or in the decision to publish the results.

\section{Abbreviations}

The following abbreviations are used in this manuscript:

$\begin{array}{ll}\text { AGR } & \text { Advanced Gas-cooled Reactor } \\ \text { BECCS } & \text { Bioenergy with Carbon Capture and Storage } \\ \text { BEV } & \text { Battery Electric Vehicle } \\ \text { BWR } & \text { Boiling Water Reactor } \\ \text { CCS } & \text { Carbon Capture and Storage } \\ \text { DACCS } & \text { Direct Air Capture of CO } \text { }_{2} \text { with Storage } \\ \text { EV } & \text { Electric Vehicle } \\ \text { FR } & \text { Fast Reactor } \\ \text { GFR } & \text { Gas-cooled Fast Reactor } \\ \text { GGR } & \text { Greenhouse Gas Removal } \\ \text { GHG } & \text { Greenhouse Gas } \\ \text { GWd } & \text { Gigawatt days } \\ \text { HTR } & \text { High Temperature Reactor } \\ \text { I-S } & \text { Iodine-Sulphur } \\ \text { LMFR } & \text { Liquid Metal Fast Reactor } \\ \text { LWR } & \text { Light Water Reactor } \\ \text { MOX } & \text { Mixed Oxide } \\ \text { MSR } & \text { Molten Salt Reactor } \\ \text { NPP } & \text { Nuclear Power Plant } \\ \text { PWR } & \text { Pressurised Water Reactor } \\ \text { SCWR } & \text { Supercritical Water Reactor } \\ \text { SFR } & \text { Sodium-cooled Fast Reactor } \\ \text { SM-HTR } & \text { Small Modular High Temperature Reactor } \\ \text { SM-LWR } & \text { Small Modular Light Water Reactor } \\ \text { SM-SFR } & \text { Small Modular Sodium-cooled Fast Reactor } \\ \text { tHM } & \text { tonnes of Heavy Metal } \\ \text { VHLW } & \text { Vitrified High Level Waste } \\ \text { VHTR } & \text { Very High Temperature Reactor } \\ & \end{array}$

\section{References}

1. Gregg, R.; Hesketh, K. The benefits of a fast reactor closed fuel cycle in the UK. In Proceedings of the GLOBAL 2013: International Nuclear Fuel Cycle Conference-Nuclear Energy at a Crossroads, Salt Lake City, UT, USA, 29 September-3 October 2013.

2. Wigeland, R.; Taiwo, T.; Ludewig, H.; Todosow, M.; Halsey, W.; Gehin, J.; Jubin, R.; Buelt, J.; Stockinger, S.; Jenni, K.; et al. Nuclear Fuel Cycle Evaluation and Screening-Final Report; FCRD-FCO-2014-000106; U.S. Department of Energy: Washington, DC, USA, 2014.

3. Chabert, C.; Tiphine, M.; Krivtchik, G.; Allou, A.; Saturnin, A.; Girotto, J.; Sarrat, P.; Hancok, H.; Mathonniere, G.; Gabriel, S.; et al. Considerations on industrial feasibility of scenarios with the progressive deployment of Pu multi-recycling in SFRs in the French nuclear power fleet. In Proceedings of the GLOBAL 2015: Nuclear Fuel Cycle for a Low-Carbon Future, Paris, France, 21-24 September 2015.

4. Hesketh, K.; Gregg, R.; Butler, G.; Worrall, A. Key conclusions from UK strategic assessment studies of fast reactor fuel cycles. Ann. Nucl. Energy 2017, 110, 330-337. [CrossRef]

5. HM Government. 2050 Pathways Analysis; Technical Report; Department of Energy and Climate Change: London, UK, 2010. 
6. Gregg, R.; Grove, C. Analysis of the UK nuclear fission roadmap using the ORION fuel cycle modelling code. In Proceedings of the IChemE Nuclear Fuel Cycle Conference, Manchester, UK, 23-25 April 2012.

7. Committee on Climate Change. Net Zero: The UK's Contribution to Stopping Global Warming; Technical Report; Committee on Climate Change: London, UK, 2019.

8. The Clean Growth Strategy Leading the Way to a Low Carbon Future; Technical Report; Department for Business, Energy and Industrial Strategy: London, UK, 2017.

9. Steinberg, D.; Bielen, D.; Eichman, J.; Eurek, K.; Logan, J.; Mai, T.; McMillan, C.; Parker, A.; Vimmerstedt, L.; Wilson, E. Electrification and Decarbonization: Exploring US Energy Use and Greenhouse Gas Emissions in Scenarios with Widespread Electrification and Power Sector Decarbonization; Technical Report; National Renewable Energy Lab. (NREL): Golden, CO, USA, 2017.

10. EPRI. U.S. National Electrification Assessment; Technical Report; EPRI: Washington, DC, USA, 2018.

11. National Grid. Future Energy Scenarios; Technical Report; National Grid: Warwick, UK, 2020.

12. BEIS. Digest of UK Energy Statistics (DUKES) 2020. Available online: https://www.gov.uk/government/ statistics / digest-of-uk-energy-statistics-dukes-2020 (accessed on 19 November 2020).

13. WNA. Nuclear Power in the USA. 2020. Available online: https://www.world-nuclear.org/informationlibrary / country-profiles / countries-t-z/usa-nuclear-power.aspx\#: :text=Nuclear (accessed on 22 July 2020).

14. Peakman, A.; Merk, B.; Hesketh, K. The Potential of Pressurised Water Reactors to Provide Flexible Response in Future Electricity Grids. Energies 2020, 13, 941. [CrossRef]

15. MacKay, D. Sustainable Energy —Without the Hot Air; UIT Cambridge: Cambridge, UK, 2008; pp. 1-384.

16. IAEA. Nuclear Power Reactors in the World 2019 Edition; Technical Report; IAEA: Vienna, Austria, 2019.

17. BEIS. Advanced Gas-Cooled Reactor (AGR) Decommissioning; Technical Report; Department for Business, Energy and Industrial Strategy: London, UK, 2019.

18. NDA. Calder Hall Nuclear Power Station Feasibility Study; Technical Report; NDA: Oxford, UK, 2007.

19. IAEA. Nuclear Heat Applications: Design Aspects and Operating Experience; Technical Report; IAEA: Vienna, Austria, 1998.

20. Frost, B.R. Nuclear Fuel Elements; Pergamon Press Ltd.: Oxford, UK, 1982.

21. DECC 2050 Calculator. 2020. Available online: http://classic.2050.org.uk/pathways/ p1112111111111111414134113413111334112111212411211111/primary_energy_chart/comparator/ 1011111111111110111111001111110111101101101110110111 (accessed on 4 May 2020).

22. Allwood, J.; Cullen, J. Sustainable Materials with Both Eyes Open; UIT Cambridge: Cambridge, UK, 2012.

23. Peakman, A.; Merk, B. The Role of Nuclear Power in Meeting Current and Future Industrial Process Heat Demands. Energies 2019, 12, 3664. [CrossRef]

24. DECC. The Future of Heating: Meeting the Challenge; Technical Report; Department of Energy and Climate Change: London, UK, 2013.

25. Rehfeldt, M.; Fleiter, T.; Toro, F. A bottom-up estimation of the heating and cooling demand in European industry. Energy Effic. 2018, 11, 1057-1082. [CrossRef]

26. DECC. The Future of Heating: Meeting the Challenge-Evidence Annex; Technical Report; Department of Energy and Climate Change: London, UK, 2013.

27. Finan, A.; Miu, K.; Kadak, A. Nuclear Technology and Canadian Oil Sands; Integration of Nuclear Power with In-Situ Oil Extraction. In Proceedings of the 2006 International Congress on Advances in Nuclear Power Plants, ICAPP06, Reno, Nevada, 4-8 June 2006; pp. 2329-2338.

28. Jasserand, F.; de Lavergne, J.G.D. Initial economic appraisal of nuclear district heating in France. In Proceedings of GLOBAL 2015-21st International Conference \& Exhibition:Nuclear Fuel Cycle for a Low-Carbon Future, Paris, France, 21-24 September 2015.

29. Parsons Brinckerhoff. Industrial Decarbonisation and Energy Efficiency Roadmaps to 2050: Oil Refining; Technical Report; Department of Energy and Climate Change: London, UK, 2015.

30. NNL. Assessment of Emerging SMR Technologies: Summary Report; Technical Report; Department of Energy and Climate Change: London, UK, 2016.

31. ESC. Nuclear for Net Zero: A UK Whole Energy System Appraisal_Project Summary Report; Technical Report; Energy Systems Catapult: Birmingham, UK, 2020.

32. Lindley, B.A.; Fiorina, C.; Gregg, R.; Franceschini, F.; Parks, G.T. The effectiveness of full actinide recycle as a nuclear waste management strategy when implemented over a limited timeframe-Part I: Uranium fuel cycle. Prog. Nucl. Energy 2015, 85, 498-510. [CrossRef] 
33. Devezeaux de Lavergne, J.; Mathonnière, G. A Global Assessment of Fast Reactors in the Future. 2015. Available online: https://www-pub.iaea.org/MTCD/Publications/PDF/AdditionalVolumes/ Pub1665Vol2Web.pdf (accessed on 19 November 2020).

34. Buiron, L.; Fontaine, B.; Andriolo, L. Transmutation abilities of the SFR low void effect core concept'CFV'3600 MWth. In Proceedings of the 2012 International Congress on Advances in Nuclear Power Plants-ICAPP'12, Chicago, IL, USA, 24-28 June 2012.

35. Ingremeau, J.; Cordiez, M. Flexblue ${ }^{\circledR}$ core design: Optimisation of fuel poisoning for a soluble boron free core with full or half core refuelling. EPJ Nucl. Sci. Technol. 2015, 1 ,11. [CrossRef]

36. Liao, J.; Kucukboyaci, V.; Wright, R. Development of a LOCA safety analysis evaluation model for the Westinghouse Small Modular Reactor. Ann. Nucl. Energy 2016, 98, 61-73. [CrossRef]

37. NuScale. Technology Overview. Technol. Overview 2018. Available online: https://www.nuscalepower.com/ technology/technology-overview (accessed on 25 November 2018).

38. Zhu, D.; Xiang, Q.; Zhang, M.; Deng, C.; Deng, J.; Jiang, G.; Yu, H. Evaluation of in-vessel corium retention margin for small modular reactor ACP100. Ann. Nucl. Energy 2016, 94, 684-690. [CrossRef]

39. Salvatores, M.; Palmiotti, G. Radioactive waste partitioning and transmutation within advanced fuel cycles: Achievements and challenges. Prog. Part. Nucl. Phys. 2011, 66, 144-166. [CrossRef]

40. Greneche, D. RED-IMPACT: Impact of Partitioning, Transmutation and Waste Reduction technologies on the Final Nuclear Waste Disposal; Synthesis Report; Forschungszentrum Jülich: Jülich, Germany, 2008; Volume 15.

41. CEA. Report on Sustainable Radioactive Waste Management; Technical Report; CEA: Saclay, France, 2012.

42. OECD-NEA. Minor Actinide Burning in Thermal Reactors; Technical Report; OECD-NEA: Paris, France, 2013.

43. NEA. Uranium 2016: Resources, Production and Demand; Technical Report; OECD-NEA: Paris, France, 2016.

44. de Zwaan, S. Feasibility Study of the U-Battery 2007. PNR-131-2007-004. Available online: http:/ / www. janleenkloosterman.nl/reports/pnr-131-2007-004.pdf (accessed on 19 November 2020).

45. Ding, M.; Kloosterman, J.L.; Kooijman, T.; Linssen, R.; Abram, T.; Marsden, B.; Wickham, T. Design of a U-Battery. Delft Tech. Univ. Delft Tech. Rep. 2011. Available online: http://www.janleenkloosterman.nl/ reports/ubattery_final_201111.pdf (accessed on 19 November 2020).

46. Neall, F.; Bennett, D.; Jones, A.; Wilson, J. Understanding the Evolution of the Carbon Component of the Dragon Reactor Fuel During the Post-Closure Phase of Geological Disposal. 2015. Available online: https:/ / rwm.nda.gov.uk/publication/understanding-the-evolution-of-the-carboncomponent-of-the-dragon-reactor-fuel-during-the-post-closure-phase-of-geological-disposal-2/ (accessed on 19 November 2020).

47. Blanchet, D.; Fontaine, B. Impact of the control rod consumption on the reactivity control of a SFR break-even core. In Proceedings of the 2012 International Congress on Advances in Nuclear Power Plants-ICAPP'12, Chicago, IL, USA, 24-28 June 2012.

48. Varaine, F.; Marsault, P.; Chenaud, M.S.; Bernardin, B.; Conti, A.; Sciora, P.; Venard, C.; Fontaine, B.; Devictor, N.; Martin, L.; et al. Pre-conceptual design study of ASTRID core. In Proceedings of the 2012 International Congress on Advances in Nuclear Power Plants-ICAPP'12, Chicago, IL, USA, 24-28 June 2012.

49. Sciora, P.; Blanchet, D.; Buiron, L.; Fontaine, B.; Vanier, M.; Varaine, F.; Venard, C.; Massara, S.; Scholer, A.C.; Verrier, D. Low void effect core design applied on $2400 \mathrm{MWth}$ SFR reactor. In Proceedings of the International Congress on Advances in Nuclear Power Plants (ICAPP), Nice, France, 2-6 May 2011; Volume 595.

50. da Cruz, D.; Rochman, D.; Koning, A. Propagation of nuclear data uncertainty for a control rod ejection accident using the total monte-carlo method. In Proceedings of the International Conference on Physics of Reactors (PHYSOR 2014), Japan Atomic Energy Agency, Kyoto, Japan, 28 September-3 October 2014.

51. Baron, D.D.; Hallstadius, L. Fuel Performance of Light Water Reactors (Uranium Oxide and MOX). In Comprehensive Nuclear Materials; Elsevier: Amsterdam, The Netherlands, 2012; Chapter 2.19, pp. 481-514.

52. Peakman, A.; Grove, C.; Fitzgerald, K.; Gregg, R. Development of an equilibrium loading pattern and whole-core fuel performance assessment in the Advanced Boiling Water Reactor (ABWR) with UO2 and U3Si2 fuels. Prog. Nucl. Energy 2019, 117, 103053. [CrossRef]

53. RWM. Generic Design Assessment: Summary of Disposability Assessment for Wastes and Spent Fuel Arising from Operation of the UK ABWR; Technical Report; NDA: Oxford, UK, 2011.

54. Harrison, M.T. Vitrification of high level waste in the UK. Procedia Mater. Sci. 2014, 7, 10-15. [CrossRef]

55. Bond, A.; Watson, S. Understanding the Post-Closure Thermal Impact of HLW/SF Waste Packages; Technical Report; NDA: Oxford, UK, 2012. 
56. CCC. Net Zero-Technical Report; Technical Report; Committee on Climate Change: London, UK, 2019.

57. RAE. Greenhouse Gas Removal; Technical Report; Royal Academy of Engineering: London, UK, 2018.

58. CCC. Hydrogen in a Low-Carbon Economy; Technical Report; Committee on Climate Change: London, UK, 2018.

59. Acar, C.; Dincer, I. Comparative assessment of hydrogen production methods from renewable and non-renewable sources. Int. J. Hydroen Energy 2014, 39, 1-12. [CrossRef]

60. Merk, B.; Litskevich, D.; Whittle, K.R.; Bankhead, M.; Taylor, R.J.; Mathers, D. On a Long Term Strategy for the Success of Nuclear Power. Energies 2017, 10, 867. [CrossRef]

61. Waltar, A.E.; Todd, D.R.; Tsvetkov, P.V. Fast Spectrum Reactors; Springer: Berlin/Heidelberg, Germany, 2011.

62. Mazzini, G.; Bomboni, E.; Cerullo, N.; Fridman, E.; Lomonaco, G.; Shwageraus, E. The use of Th in HTR: State of the art and implementation in Th/Pu fuel cycles. Sci. Technol. Nucl. Install. 2009, 2009. [CrossRef]

63. Talamo, A.; Gudowski, W. Performance of the gas turbine-modular helium reactor fuelled with different types of fertile TRISO particles. Ann. Nucl. Energy 2005, 32, 1719-1749. [CrossRef]

64. Utilization of thorium in a Gas Turbine-Modular Helium Reactor. Energy Convers. Manag. 2012, 63, 25-30. [CrossRef]

65. Chang, H.; Yang, Y.; Jing, X.; Xu, Y. Thorium-Based Fuel Cycles in the Modular High Temperature Reactor. Tsinghua Sci. Technol. 2006, 11, 731-738. [CrossRef]

66. Attom, A.M.; Wang, J.; Yan, C.; Ding, M. Neutronic analysis of thorium MOX fuel blocks with different driver fuels in advanced block-type HTRs. Ann. Nucl. Energy 2019, 129, 101-109. [CrossRef]

Publisher's Note: MDPI stays neutral with regard to jurisdictional claims in published maps and institutional affiliations. 